\title{
A inserção dos homens nos estudos de gênero: contribuições de um sujeito histórico
}

\author{
Men's entrance into gender studies: \\ contributions of an historical subject
}

\begin{abstract}
This article presents concepts and questions of gender that were proposed by men who were present at the moment that feminism reappeared in central countries in the 1960s, and who participated in men's groups in the 1970s. Situated as subjects of knowledge/of gender in the context of the critical debates that were widelydisseminated at that time, they adopted a dialectical and historical view of social reality, making contributions that helped de-construct the binary focus which had prevailed up till that point.
\end{abstract}

Key words Men, Masculine gender, Social dialectics
Resumo Este artigo resgata conceitos e discussões sobre as questões de gênero que foram apresentados por homens que presenciaram o (res) surgimento do movimento feminista nos países centrais nos anos 60, e participaram de grupos de homens nos anos 70. Situados como sujeitos do conhecimento/de gênero no contexto dos debates críticos sobre a sociedade contemporânea, que foram amplamente disseminados naquela época, adotaram uma visão dialética e histórica da realidade social, trazendo contribuições que ajudaram a desconstruir a ótica binária antes prevalecente.

Palavras-chave Homens, Gênero masculino, Dialética social

1 Núcleo de Gênero e Saúde, Departamento de Ciências Sociais, Escola Nacional de Saúde Pública, Fiocruz. Rua Leopoldo Bulhões, 1.480/9o andar, Manguinhos, 21041-210, Rio de Janeiro RJ. karengi@ensp.fiocruz.br 


\section{Introdução ao momento inaugural: anos 60}

A questão do masculino emergiu com força nos estudos de gênero no Brasil nos últimos anos, especialmente nas discussões e análises sobre sexualidade e saúde reprodutiva, dominadas até então por mulheres (para revisões recentes da literatura brasileira e latino-americana, ver: Giffin e Cavalcanti, 1999; Vigoya, 2001; Beattie, 2002). Mas, mesmo durante os primeiros anos do ressurgimento do feminismo nos anos $60 \mathrm{e}$ do início dos "estudos das mulheres", antes do desenvolvimento do conceito de gênero, havia homens interessados em participar da reflexão sobre essas questões. Sua aproximação às discussões em pequenos grupos e seminários, no entanto, foi vetada naquele momento por nós, mulheres. Exercer este poder de veto foi visto como necessário, ao menos num primeiro momento, dada nossa experiência cotidiana com a dominação masculina.

Participantes do então-chamado movimento de "libertação feminina", denunciamos a divisão sexual do trabalho que trouxe junto a definição das mulheres como mães/reprodutoras, um duplo moral sexual, e nosso afastamento dos espaços socialmente valorizados da esfera pública. A "libertação" que queríamos era desta definição, hegemônica - mas na experiência vivida, já havíamos saído da esfera doméstica/reprodutiva: muitas foram ou tinham sido ativistas em espaços da esquerda ou universitários, no movimento anti-nuclear, anti-guerra, ou de "direitos civis"isto é, contra o regime de apartheid racial nos Estados Unidos. Além de estar atuando na política e no público, a importância da questão do aborto indicava que nossa sexualidade também já não estava atrelada aos padrões reprodutivos antes esperados, assim como os dados sobre a força de trabalho em geral revelaram que muitas mulheres não estavam exatamente confinadas ao lar.

A facilidade com a qual recusamos a participação dos homens nas nossas discussões oferece um contraste agudo com o tratamento dado ao poder masculino como objeto central das análises subseqüentes, nos estudos de gênero feitos pelas mulheres. Nestes estudos, foi-se descobrindo e esmiuçando o esquema binário que organizava nosso mundo: na oposição e hierarquização de cultural/natural, social/biológico, ciência/arte, razão/emoção, produção/reprodução, público/privado, ativo/passivo, corpo/mente etc. consolidou-se a noção de dois "sexos opostos".
Durante anos os homens foram inseridos como objeto nos estudos segundo este modelo, freqüentemente referido como "patriarcal": racional, ativo no público, na produção da ciência e da cultura, provedor, sexualmente "irresponsável", poderoso, universalizado na sua dominação, Homem com 'H' maiúsculo. O outro lado desta moeda é a Mulher: emotiva, voltada ao mundo privado da reprodução dos filhos, cuidando das relações de afeto, sexualmente passiva, dependente, obediente, universalizada na sua opressão. Na confrontação entre Homem e Mulher nas relações sociais, fossem na esfera doméstica ou no público, as vantagens todas, segundo os valores dominantes da sociedade individualista, competitiva e monetarizada, pareciam ser dos Homens.

É importante lembrar que o ressurgimento da "questão da mulher" ocorreu em países centrais do capitalismo que haviam vivido duas décadas de crescimento econômico pós-guerra, o que ampliou a demanda no mercado de trabalho urbano de "colarinho-branco" para jovens mulheres com alguma instrução e permitiu a incorporação de importantes segmentos na sociedade de consumo, além de avanços na institucionalização de políticas de proteção ao trabalhador e do bem-estar social, o que também aumentou a demanda para trabalhadoras qualificadas.

Mas já na década de 1950 havia surgido a figura dos jovens americanos "rebeldes sem causa" - insatisfeitos, embora tendo um nível de vida e segurança material admirável - e que foi seguido, nos anos 60 , pelo livro-manifestação da Betty Friedan (1963), que expôs o "problema sem nome" das esposas de classe média americana, com diplomas universitários mas isoladas com seus filhos pequenos nas suas bem-equipadas casas suburbanas.

As insatisfações "sem causa" e "sem nome" dessa geração foram explicitadas com a explosão da "contra-cultura" que se manifestou no repúdio daquele que foi nomeado pela ala esquerda de "complexo militar-industrial", com sua cultura individualista, consumista e competitiva, instrumentalização das relações interpessoais, família "patriarcal" repressora e violência institucionalizada. Esta revolta abrigou não só mulheres, mas também gays, hippies, jovens das esquerdas, universitários, e outros segmentos sociais, levando à repressão e, no extremo, à morte de estudantes universitários nos Estados Unidos. Não sendo monolítico, mas sim crítico e contra-hegemônico, este processo alastrou ao ponto de ser historicamente caracterizado co- 
mo sendo de toda uma geração que dizia "não" aos valores dominantes da ordem social instituída - pelo menos naquele momento.

Foi neste contexto histórico que nós, feministas, afastamos os homens e criamos espaços públicos exclusivamente femininos, nos quais enfocamos nossa falta de poder nas relações com os homens. A contradição inerente a este movimento não tem sido reconhecida, a complexidade de seu contexto socio-histórico é pouco analisada, e até parece que o fato histórico em si é desconhecido pelas novas gerações.

Entendo que a obsessão feminista com o poder masculino foi produtiva e necessária, no sentido de trazer à visibilidade estruturas e relações sistêmicas de poder que foram legitimadas pela ciência e naturalizadas nas ideologias de gênero binárias, dominantes. Afinal, os estudos de gênero mostraram que tais idéias binárias, expressas em símbolos e normas sociais, estruturaram instituições, foram oficializadas em leis, e encarnaram em identidades pessoais, ou seja, participaram e participam da construção de uma realidade social, são aspectos da nossa ordem social. Quem começa a perceber sua onipresença poderia até desconfiar que são eternos... No entanto, ao representar todos os homens como poderosos e todas as mulheres oprimidas, estávamos reproduzindo o binarismo.

Ao mesmo tempo, a denúncia "o pessoal é político”, que surgiu dos grupos de reflexão, inaugurou um interesse persistente da sociologia feminista na interface entre estruturas, experiência relacional e subjetividade (Lengerman \& Niebrugge-Brantley, 1990). Isto, com o tempo, fortalecera o que tem sido considerado um "novo paradigma” nas ciências sociais (Ritzer, 1990) uma perspectiva que relativiza as dicotomias binárias e afirma uma relação dialética entre estruturas sociais (inclusive estruturas ideológicas) e sujeitos (ver, por exemplo, Jessop, 1996). Esta perspectiva permite perceber a construção mútua de sujeitos e realidade social e um processo constante de resistência e acomodação às representações dominantes, do qual o sujeito do feminismo é um excelente exemplo.

Apesar da extraordinária produtividade e diversidade dos estudos de gênero, o tema da entrada dos homens nos estudos de gênero representa uma oportunidade muito bem-vinda de valorizar outras perspectivas - coerente com a importância dada na epistemologia feminista à natureza sempre parcial e situada dos conhecimentos, que devem ser vistos como contextualizados historicamente (Haraway, 1988).
Neste intuito, pretendo aqui resgatar discussões sobre as questões de gênero a partir de autores homens que viveram esse período inaugural, sujeitos históricos da emergência dessas questões, nesses países centrais, buscando suas visões das questões de gênero e das raízes sociohistóricas da preocupação contemporânea com a masculinidade. Sendo o campo dos estudos de gênero extremamente diversificado, em que parece haver um consenso (talvez o único!) sobre a noção das relações de gênero serem "construções sociais", interessa aqui examinar autores cujas perspectivas teóricas oferecem elementos para entender, concreta e historicamente, a construção e reconstrução dessas relações.

\section{A fala dos homens}

Nos anos 70, com o movimento feminista e os estudos de mulheres prosseguindo a todo vapor, e com homens do movimento e dos estudos gays insistindo que os homens heterossexuais eram todos candidatos à liberação, a hegemonia das ideologias binárias/da dominação masculina se viu sob séria contestação. No âmbito universitário e em outros espaços da classe média, formaram-se coletivos de homens dedicados à reflexão sobre sua própria experiência no patriarcado, que assumiram as críticas e reconheceram como seus os hábitos masculinos de dominação e desvalorização. Segundo os participantes, havia sentimentos de muita culpa; como no feminismo, havia discordância e conflito.

Uma coletânea (Beyond patriarchy: essays by men on pleasure, power and change, 1987), feita por participantes desse processo, tanto gays como heterossexuais, afirma a centralidade da questão do "poder", mas enfatiza a modificação constante dos padrões de dominação, a internalização de estruturas sociais de opressão e poder, e a necessidade e dificuldade de entender $a$ inter-relação entre opressão no nivel individual e as grandes estruturas sociais, politicas, econômicas e ideológicas baseadas na hierarquia e nos privilégios (Kaufman, 1987).

Sem negar a dominação dos homens, Kaufman aponta que os homens são marcados e brutalizados pelo mesmo sistema que os dá seus privilégios e poder: A vida de trabalho cotidiana de sociedades de classe industrializadas é de violência. Violência se disfarça de racionalidade econômica; enquanto alguns de nós são feitos extensões de máquinas, outros são feitos cérebros separados de corpos... é a violência que expõe traba- 
lhadores aos perigos de substâncias químicas, radiação, máquinas, ritmos acelerados, e distensão muscular. É a violência que condena a maioria a trabalhar até a exaustão durante 40 ou 50 anos até ser jogada na lata de lixo como velho e gasto. (Kaufman, 1987).

Kaufman argumenta que a "tríade de violência" - de um homem contra mulheres, contra outros homens, e contra si mesmo - reflete a violência cotidiana de uma sociedade de classes hierárquica, autoritária, sexista, classista, militarista, racista, impessoal e louca canalizada através de um homem individual. Sob esta ótica, a forma de dominação peculiar à nossa época não é mais a autoridade patriarcal, mas sim a transformação de todas as relações em formas instrumentais e impessoais. Entre outras coisas, isto implica que a masculinidade requer a supressão de muitas necessidades, sentimentos, e formas de expressão, o que faz esta construção social ser aterrorizadoramente frágil. O resultado é uma “tensão" entre ser macho e ser masculino, capaz de manter uma insegurança constante nos homens, e impulsionar tanto a auto-desvalorização como reações violentas contra outra/os.

Uma revisão de literatura sobre o gênero masculino (Carrigan, Connell \& Lee, 1987) aponta estudos norte-americanos que, desde os anos 50 (portanto antes do feminismo), relacionam a questão do pai ausente com a delinqüência e fracasso escolar dos filhos, especialmente em famílias pobres. Há também estudos dos novos conflitos na masculinidade relacionados a novas demandas, principalmente perante homens na classe média, para sutilezas e sensibilidades antes consideradas femininas, nas relações sociais e afetivas. A partir de 1970, já se encontra na literatura afirmação de contradições entre a identidade masculina hegemônica e as condições reais de vida dos homens (incluindo a alienação no trabalho, a burocracia política e militar, e a comercialização da sexualidade, segundo Bedarnik, 1970; apud Carrigan, Connell e Lee, 1987) o que leva à visibilidade a questão das restrições e desvantagens de ser homem.

Esses autores criticam a perda de radicalidade do pequeno movimento de liberação dos homens [que está agora]... preocupado em encontrar maneiras do grupo dominante - homens brancos, instruidos, heterossexuais, e abastados ...se adaptar às circunstâncias novas (ibidem). Denunciam que o interesse predominante destes grupos, revelado em 29 livros publicados nessa década sobre o tema, está na modernização da masculinidade hegemônica... e seu méto- do terapêutico, voltado para transformações nas suas relações pessoais ... sem destruir os arranjos socio-estruturais que de fato dão o seu poder (Carrigan, Connell, Lee, 1987).

Esses autores argumentam que a história da identidade homossexual masculina, tida como tipo de pessoa apenas a partir do século 19, oferece um ponto de partida para uma perspectiva histórica sobre a masculinidade como ...constantemente construída dentro da história de uma estrutura social em evolução. Apontam que os primeiros homens a se alinharem com o movimento de libertação feminista e aplicar suas técnicas de reflexão foram os ativistas gays. Também produto dos estudos gays, o conceito de masculinidade hegemônica sugere que são grupos específicos de homens, não os homens em geral, que são oprimidos no âmbito das relações patriarcais sexuais (ibidem).

A partir deste ponto de vista conceitual, lembram que as relações homem/mulher não são embates entre blocos homogêneos, e que a construção da hegemonia faz parte de uma ampla luta social, sendo ...uma questão de como grupos específicos de homens habitam posições de poder e riqueza e como eles legitimam e reproduzem as relações sociais que geram sua dominação (ibidem). Explicitam que a hegemonia implica persuasão, e envolve uma divisão de trabalho e o Estado na reconstrução constante das relações de gênero, como parte da re/produção do sistema no qual a dominação de alguns é gerada.

Michael Kimmel oferece uma análise histórica de imagens da masculinidade nos Estados Unidos, cujas características comuns de violência, competitividade extrema, e insegurança podem ser relacionadas à política externa agressiva e imperialista do país: ....agressão e violência compõem esta masculinidade compulsiva, uma identidade de gênero socialmente construída que se manifesta tanto em comportamento individual como na política doméstica e externa. O argumento central deste artigo é que a masculinidade compulsiva nos Estados Unidos faz deste país um perigo no mundo moderno (Kimmel, 1987).

Postula que os Estados Unidos têm sido um país arquetipicamente macho, tanto porque a masculinidade tradicional (do cowboy, domador da natureza e dos povos nativos na abertura da fronteira, e que nunca forma laços afetivos) permeia toda a faceta da vida política, como ...porque os homens americanos nunca estão seguros da nossa masculinidade, sempre inquietos, eternamente ansiosos, incessantemente competitivos (ibidem). 
Com a ocupação de todo o território americano, políticos e presidentes, preocupados em reforçar a masculinidade, em 1910 instituíram os Escoteiros e descobriram, nas suas novas aventuras imperialistas, uma nova fronteira para dominar. Desde o fim da Segunda Guerra Mundial, a guerra fria e a corrida espacial continuaram a concorrência para a dominação. Mas nos anos 80 , com os conservadores americanos, inclusive, se colocando contra a invasão da América Central e com manifestações anti-nucleares na Europa, o autor manifesta esperança que os Estados Unidos possam se tornar, finalmente, uma democracia preocupada com a dignidade humana e a justiça. No entanto, em artigo dos anos 90, a continuação da análise das modificações históricas aponta que a definição da virilidade norte-americana dominante foi transferida para o mercado, e que La definición hegemónica de la virilidad es un hombre en el poder, un hombre con poder, y un hombre de poder. (Kimmel, 1997).

Para Kimmel, embora as masculinidades variem com diferenciações internas de raça, classe, idade, etnia ou orientação sexual, todas significam no ser como las mujeres. Isto leva a condutas exageradamente masculinas, e instaura uma incertidumbre crónica sobre la identidad de género (ibidem), que precisa ser resolvida perante outros homens. Sendo a masculinidade dependente da aprovação de outros homens, .su emoción más destacada es el miedo, o que situa a homofobia como princípio organizador da definição de virilidade (ibidem). Nesta dinâmica, o medo leva à vergonha, ao silêncio, e à violenta afirmação da masculinidade.

Enquanto as mulheres e os homens gays são "outros" destacados desta identidade heterossexual, Kimmel identifica ainda outras categorias de homens que, através da história, ... han servido como modelos de poco-hombres contra los cuales los estadounidenses han lanzado su rabia genérica (ibidem). São homens, não somente de outros países, como também nativos indígenas e imigrantes italianos, judeus, irlandeses, africanos, e asiáticos nos Estados Unidos. Desta forma, a virilidade só é possível para una minoría particular, y la definición ha sido construida para prevenir que los outros la logren (ibidem). Nesta análise, a própria definição da masculinidade hegemônica é um dispositivo de dominação internacional e de classe social.

Horowitz \& Kaufman (1987) enfocam a sexualidade masculina e a pornografia, contextualizadas na sociedade capitalista de consumo, em que relações humanas são dominadas pela mercantilização: Onde puder, o capitalismo produz objetos para consumo sexual e transforma em objeto os sujeitos da sexualidade para vender outros produtos. Na medida em que o binarismo "passivo/ativo" proíbe e suprime a passividade nos homens, esta masculinidade é ... a ideologia da sociedade patriarcal, de mais repressão, capturada na personalidade do indivíduo (ibidem). A fascinação com a pornografia nesta situação compõe um mercado insaciável, que oferece não somente um objeto sexual passivo, mas a oportunidade de os homens terem prazer sexual de forma passiva. A conclusão dos autores destaca que os danos não atingem apenas os homens: A raiz do problema é uma cultura patriarcal, orientada ao lucro, produtora de mercadorias, de mais repressão, que reprime a polissexualidade e superimpõe a masculinidade e a feminilidade ao dualismo ativo/passivo; estas são as fontes últimas da degradação sexual de mulheres e de mais repressão de toda humanidade (ibidem).

Wernick, em outro artigo que interroga a sociedade de consumo, aborda a imagem dos homens na propaganda comercial, e constata uma mudança: da imagem masculina antes predominante de "voyeur" que objetivava as mulheres, a uma representação narcisista do homem objeto, consumidor de produtos de beleza pessoal, roupas, equipamentos de lazer, etc. Segundo este autor, as novas imagens refletem mudanças que ocorreram no padrão patriarcal neste contexto social: enquanto a dominação masculina perdura na esfera pública, os homens perderam seus privilégios automáticos; ainda ganham mais que as mulheres, mas não são mais definidos como provedores; a heterossexualidade ainda é normativa, mas no jargão do mercado, a homossexualidade está se transformando em um estilo de vida aceitável (Werneck, 1987).

Werneck situa estas mudanças como profundamente articuladas na disputa mais geral pela riqueza, poder e status... como as mulheres antes deles, os homens estão se transformando em bens de consumo... a equalização na esfera do consumo não é nem um pouco a igualdade com a qual a gente possa sonhar, a igualdade de seres livres e autodeterminados em associação livre e autodeterminada uns com outros. É a igualdade... de personalidades auto-referentes, mas ansiosas, à venda (Wernick, 1987).

Victor Seidler (1991), que também participou deste processo histórico e escreveu sobre as relações heterossexuais, lembra que, nos anos 60 , começou o questionamento de uma socie- 
dade que subordinou as relações humanas à busca do lucro e à ambição individual. Portanto, não podemos separar nosso entendimento da família e das relações sexuais do nosso entendimento do trabalho e produção. Estas não são "esferas autônomas" nem são relacionados mecanicamente... (Seidler, 1991).

Ele analisa a construção do gênero masculino a partir da sua identificação com a razão. Para competir na esfera pública, os homens são pressionados a encarnar sua porção deste modelo binário, traduzida em independência e auto-suficiência masculina, o que os leva a desvalorizar ou negar necessidades afetivas em nome desta "razão social". Ao mesmo tempo, Seidler explicita o preço pago por eles em assumir esta identidade: sendo as emoções e sentimentos fontes importantes de dignidade e integridade humana, negá-los institui a fragmentação de um ser dividido contra si. Tentar ser este homem competitivo, racional, ambicioso, forte e independente ...freqüentemente significa, no minimo, distorcer nossas sensibilidades e matar nossas emoções. Significa fazer dos nossos corpos máquinas insensíveis que possamos controlar. Somos treinados desde pequenos, muito mais que as mulheres, para identificar com a ética do trabatho capitalista (ibidem).

Sua análise da lógica desta construção social aponta como, no âmbito do trabalho, os homens precisam se tratar como objetos, tanto para manter o ritmo do trabalho sobre o qual não têm controle, como na supressão de sentimentos de raiva e ressentimento que resultam da sua falta de poder nestas relações: Quando as pessoas dizem que "os homens não são oprimidos", especialmente homens heterossexuais, já que têm poder na sociedade capitalista patriarcal, não somente esquecem a natureza das relações de classe, como não investigam o poder das rotinas de produção e disciplina capitalista sobre as vidas das famílias, tanto da classe trabalhadora como da classe média. Um homem nem está livre para desenvolver uma relação mais próxima com seus filhos, se é forçado ao trabalho noturno (ibidem).

No âmbito familiar, concretizam-se as conseqüências negativas desta ênfase social no racional que desvaloriza as relações interpessoais, que refletem não somente os limites afetivos do ser fragmentado internamente, como a organização concreta da vida em geral a partir das necessidades da produção. Seidler conclui que, neste contexto, dar mais atenção à relação com os filhos e compartir o trabalho doméstico implicaria, no mínimo, lutar pela licença-paterni- dade, tempo para buscar os filhos na escola, e trabalho de tempo parcial mas com salários dignos, lutas que ele considera bem menos prováveis a partir dos anos 80 .

Seidler avança também na análise do processo histórico de reorganização do trabalho no capitalismo, incluindo a escala maior das empresas, a racionalização, especialização e fragmentação do processo, e a desqualificação do trabalho, que ele aponta como uma das fontes da crise de masculinidade. A partir da crise econômica iniciada nos anos 70, nota que o desemprego, a inflação e a diminuição dos salários na Inglaterra, além de minar esta fonte tradicional de identidade masculina, levou ao ressentimento e à re-emergência do racismo e anti-semitismo fascista, e instituiu um conflito entre as gerações. Enquanto a geração dos homens mais velhos, que havia vivido a experiência da grande depressão dos anos 30 , aceitava que tinha de trabalhar mesmo se não gostasse do trabalho, os filhos, confrontados com um processo de desqualificação e intensificação do trabalho que exige mais e traz ganhos menores, não querem acabar como ele.

Com a diminuição da gratificação possível na esfera do trabalho, houve no pós-guerra uma gradual transferência para fantasias de consumo, com o trabalho reduzido cada vez mais a uma fonte de dinheiro, acompanhando uma objetivação mais profunda do eu: Assim é que estilo e aparência se tornam tão crucial nos anos $80 \ldots$ se nossas vidas são fragmentadas, um senso de identidade é mais facilmente concebido como algo não fixo e harmonioso, mas como... algo que manufaturamos para nós mesmo, através de objetos disponíveis, tais como roupas, música, e cortes de cabelo... o eu se torna uma mercadoria... o capitalismo cada vez mais coloniza níveis mais profundas do eu (ibidem).

Conclui que nestas condições, o contato com o feminismo pode aprofundar o silêncio, a culpa, o desespero, e a violência dos homens. Opina que o processo de conscientização de homens em pequenos grupos é necessário mas não suficiente e que, de alguma forma, precisamos conectar as frustrações geradas a partir da indignidade e subordinação que as pessoas precisam agüentar no trabalho com as tensões nas nossas relações mais próximas (ibidem).

Donald Lowe (1995), analisando a questão da naturalização do modelo binário que constrói os gêneros, refere os estudos de Laqueur (1990) que mostra que um modelo de anatomia humana de dois sexos é relativamente novo, 
tendo sido introduzido no Ocidente no século 17. Argumenta, com Foucault, que é somente no século 18 , na sociedade burguesa, que a sexualidade emerge como categoria discursiva separada e que esta construção discursiva, instituindo a idéia de identidade sexual que iria construir uma hegemonia heterossexual, trouxe à baila seu outro: o homossexual. Refere estudos antropológicos que identificaram sociedades com três gêneros, e conclui que ... é somente no Ocidente moderno que gênero é concebido como categoria universal baseado na naturalidade de diferenças sexuais anatômicas (1995).

Conclui ainda, contra teóricas feministas prestigiadas, que o gênero não é universalmente uma categoria de hierarquia ou estratificação social, ao contrário, o gênero se torna uma categoria fundamental de hierarquia na ordem social apenas com o surgimento da sociedade burguesa (ibidem). Resumindo: ... duas transformações do regime disciplinar corporal ocorreram com o capitalismo industrial. Primeiro, ...o gênero, com a nova afirmação de ser baseado na natureza e com a nova ciência biológica reconhecida como o discurso da natureza, se tornou pela primeira vez na história uma categoria fundamental da organização social... Segundo, a sexualidade também tornou-se um regime discursivo novo, com sua ênfase na norma heterossexual e o vício homossexual (Lowe, 1995).

No argumento de Lowe, no capitalismo tardio de hoje, com a maioria das mulheres integradas à força de trabalho, o lar é transformado em centro de consumo, e as tarefas de reprodução social são crescentemente realizadas de forma profissional ou mercantilizadas. Separada da reprodução social; a sexualidade torna-se um signo que potencializa o consumo. Livre da reprodução social, a sexualidade nova começa a ser explorada pelos fins de consumo no capitalismo tardio. É isto que [a]... distingue da regulamentação burguesa do capitalismo industrial que Foucault estudou. Ela torna público a promessa de prazer sexual, contradizendo a sexualidade repressora, disciplinadora (ibidem).

A proliferação de estilos de vida sexuais potencializa o consumo de artigos que tornam visíveis esses estilos, ao mesmo tempo em que a venda de mercadorias em geral é potencializada por imagens sexuais: ... a sexualidade bipolar está sob ataque da mercantilização da sexualidade e a sexualização do consumo no capitalismo tardio... Dada a relação entre sexos e gêneros binários, conclui que Estes desenvolvimentos novos estão subvertendo os fundamentos estruturais sobre os quais se apoiou a construção bipolar burguesa dos gêneros (ibidem).

Sob esta ótica, estamos entrando em um período histórico que desata os velhos nós do gênero binário, mas sob a hegemonia daquilo que os marxistas chamam de hegemonia de práticas de troca, isto é, práticas ditadas pela acumulação de capital ou os não-marxistas chamam de mercado livre, um sistema que não se preocupa com o desenvolvimento do ser ou a satisfação de necessidades humanas (ibidem).

Robert Connell, um dos teóricos mais conhecidos dessa geração, argumenta no seu livro Gênero e poder (1987) que as estruturas de trabalho, poder e catexia juntos articulam a estrutura das relações de gênero, compondo um arcabouço conceitual amplo, necessário para analisar as questões de gênero.

$\mathrm{Na}$ sua discussão da masculinidade hegemônica, avança no entendimento que esta imagem não corresponde necessariamente às características dos homens de fato mais poderosos: $A$ face pública da masculinidade hegemônica não é, necessariamente, o que os homens mais poderosos são, mas aquilo que sustenta seu poder, e aquilo que muitos homens são motivados a apoiar (Connell, 1987). Construída em relação a mulheres e a outras masculinidades referentes a grupos dominados, a masculinidade hegemônica as oculta e as subordina, embora não as elimine por completo. Estas outras masculinidades ...não são necessariamente claramente definidas - de fato, instituir hegemonia pode consistir precisamente em prevenir que alternativas ganhem definição cultural e reconhecimento como alternativas, em confiná-las a guetos, ao privado, ao inconsciente (ibidem).

A função ideológica deste modelo é explicitado: embora não necessariamente represente a maneira de ser nem dos homens da elite nem dos homens subordinados, a cumplicidade de todos com a masculinidade hegemônica explica-se pelo fato de que é a expressão cultural da sua dominação sobre as mulheres, que legitima e naturaliza práticas de subordinação.

Nos anos 90, Connell acrescenta às estruturas básicas das relações de gênero uma quarta, as relações de simbolização (Connell, 1995b). Embora se declare relutante em escrever o que ele refere como mais um livro sobre homens (que sugere que existe um objeto estável e unificado), apresenta seu projeto intelectual, que ele define como relacionar sistematicamente a vida pessoal e a estrutura social a partir de pesquisa com três categorias de homens em situações es- 
pecíficas que não correspondem à hegemonia: participantes do movimento ecológico, jovens desempregados, e gays (Connell, 1995a).

Connell aponta que, embora a noção do provedor masculino seja historicamente datada, os estudos de gênero dos homens nos anos 70 sobre o papel social dos homens o universalizaram, presumindo que sempre foi uma parte central do ser masculino. Elogia o movimento na direção de um novo paradigma nestes estudos, enumerando seus temas comuns: a construção da masculinidade na vida cotidiana; a importância das estruturas econômicas e institucionais; o significado de diferenças entre as masculinidades e a natureza contraditória e dinâmica do gênero. Desta ótica, alerta que o reconhecimento de diversidade no masculino não é suficiente, pois Ao reconhecer masculinidades múltiplas, especialmente em uma cultura individualista como a dos Estados Unidos, há o risco de elas serem entendidas como estilos de vida alternativas, uma questão de escolhas de consumo (ibidem). Daí a importância de estudar as relações dialéticas de aliança, dominação, e subordinação que constroem as masculinidades.

Connell reivindica a volta de uma dimensão corporal nos estudos, para além de duas concepções binárias inadequadas: como máquina natural ou como superfície passiva e neutra. Afirma que há uma dimensão corporal irredutível e central na experiência de ser homem ou mulher, que não é biologicamente determinada, exemplificando com o caso de trabalhadores braçais, ...cuja vulnerabilidade vem da própria situação que os permite definir a masculinidade através do trabalho (ibidem). Embora os corpos destes trabalhadores sejam seu recurso econômico, pois é o que trocam no mercado de trabalho, esse recurso não é estável: Onde o trabalho sofre desqualificação e precarização, homens da classe trabalhadora são definidos cada vez mais como possuindo apenas força [corporal]. O processo é virulento onde exclusão classista combina com racismo... Homens da classe média, por outro lado, são crescentemente definidos como possuindo qualificações. Esta definição é apoiada por uma mudança histórica poderosa dos mercados de trabalho, o crescimento da demanda por qualificações, que seleciona e promove segundo classe social. Este processo de classe altera a conexão familiar entre masculinidade e máquinas (ibidem).

Com este exemplo, ilustra como o gênero está envolvido com uma forma de estruturar a prática social em geral. Não sendo um tipo es- pecial de prática, ...é inevitavelmente envolvido com outras estruturas sociais como classe, raça, nacionalidade ou posição na ordem mundial, e concerne questões de justiça social. E isto quer dizer que para entender o gênero, portanto, precisamos constantemente ir além do gênero (ibidem).

Connell identifica o que considera serem as tendências atuais de mudança nas estruturas de relações de gênero: nas relações de produção, o aumento da participação feminina na força de trabalho remunerada; nas relações de poder, a evidência mais visível seria ... o colapso histórico da legitimidade do poder patriarcal, e um movimento global pela emancipação de mulheres (ibidem); nas relações de catexia, a visibilidade da sexualidade gay e lésbica como alternativas na ordem heterossexual. Argumenta que a escala da violência contemporânea indica tendências a crise na ordem de gênero, mas alerta que tais tendências não levam necessariamente ao desmonte, e podem até provocar tentativas de reforçar uma masculinidade dominante.

Connell tem dado importância crescente à construção histórica das masculinidades, a partir do padrão hegemônico americano e europeu, que nos últimos 200 anos foi ... deslocado para uma masculinidade mais racional, mais calcula$d a$, melhor ajustada a uma economia industrialcapitalista e ao estado burocrático. Esta, por sua vez, tem sido contestada por formas de masculinidade que enfatizam o impulso e a violência -o fascismo nas metrópoles, as masculinidades tipo "cowboy" na fronteira. A forma hegemônica de masculinidade burguesa se dividiu entre formas que enfatizam o conhecimento especializado e formas que enfatizam a dominação e o cálculo egocêntrico. A luta por hegemonia entre elas pode ser vista na divisão entre liberais e conservadores na política burguesa (Connell, 1995b).

Lembra que a dominação destes padrões no mundo foi construída historicamente no imperialismo, a princípio na conquista direta ...que fez das relações de raça uma parte inevitável da dinâmica de gênero (ibidem). Com a criação mais recente dos mercados globais, passamos ao neocolonialismo, no qual as grandes empresas multinacionais apresentam formas de masculinidade que são hegemônicas entre seus administradores; a exportação de armas acompanha a exportação da violência organizada das masculinidades militares; e a difusão da cultura metropolitana reconstrói formas locais de sexo entre homens na base da identidade gay dos Estados Unidos urbano. Alerta que, no tempo dos grandes meios de comunicação globais contro- 
lados pelos Estados Unidos, ... el grado de unidad que se ha logrado imponer [nas masculinidades] no se debe a una evolución abstracta hacia la modernidade, sino precisamente a la discontinuidad global muy concreta del imperialismo (Connell, 1998).

Connell aponta que esta interação global cria terreno para uma nova hegemonia masculina, com a globalização das finanças, a desregulamentação dos mercados e o crescimento dos impérios empresariais fora do controle de qualquer governo e de qualquer processo democrático atualmente existente (Connell, 1995b). Indaga se esta nova masculinidade não será ... calculista, com uma abertura para a violência autoritária como uma forma de ação econômica; sensual, herdando os prazeres da masculinidade patriarcal, com muito pouco controle cultural sobre a auto-gratificação e com uma falta de vínculo notável com relacionamentos de parentesco... (ibidem). Notando que estamos numa nova fase de exploração comercial da heterossexualidade, aponta como uma das instituições da nova ordem mundial o turismo sexual internacional ...mais claramente, a prostituição das mulheres da periferia para satisfazer homens dos países industrializados (ibidem).

Afirma que não há nenhuma razão para imaginar que estas mudanças possam significar qualquer coisa de bom para as mulheres. Principalmente porque, à medida que as grandes empresas se tornam multinacionais, ...escapam às estruturas politicas nacionais através das quais as mulheres têm reivindicado uma oportunidade igual e um fim da discriminação (ibidem).

Enquanto a dominação masculina tem perdido legitimidade com a difusão mundial da cultura feminista, restaram ou até aumentaram o que Connell chama de dividendos patriarcais: os salários maiores, a representação política, a riqueza empresarial, o controle dos meios de violência. Embora pareça que os homens em geral se beneficiem deste dividendo, grupos específicos (e, podemos afirmar, cada vez mais a maioria dos homens) ganham muito pouco: por exemplo, os jovens da classe operária, economicamente despossuídos por causa do desemprego estrutural, podem não ter qualquer vantagem em relação às mulheres em suas comunidades (ibidem). Estes, junto com homens negros e gays, pagam o preço da manutenção de uma ordem de gênero não-igualitária.

Sob esta perspectiva, Connell afirma a necessidade de redefinir a direção da luta política a partir da definição explícita do mundo que es- tamos tentando produzir, pois outras forças certamente estão fazendo escolhas - escolhas que as crianças e os jovens estão enfrentando aqui e agora num bombardeio de publicidade disfarçado de esporte, de militarismo disfarçado de diversão, de sexo comercial disfarçado de liberdade pessoal (ibidem). Notando que os homens também compartilham interesses com as mulheres, argumenta que teríamos de fazer alianças, o oposto de um movimento dos homens, pois caminhar na direção da justiça social requereria enfrentar justamente os conflitos de interesses entre os diferentes grupos de homens.

\section{Considerações finais}

A entrada destes homens nos estudos de gênero, sujeitos históricos situados em um contexto em que imperava uma visão crítica característica dos anos 60, e sem negar a dominação masculina, trouxe discussões importantes sobre os preços pagos e os problemas dos homens, antes pouquíssimo visíveis no Homem universalizado, reduzido ao "poder perante as mulheres".

Adotaram uma visão dialética e histórica da realidade social dos gêneros, que relaciona o indivíduo com as ideologias e instituições sociais, sem determinismos mas também sem voluntarismos, num processo de constituição mútua, antítese da ótica binária da ciência objetivista. Nas palavras de Pierre Bourdieu, Homens e mulheres constroem o mundo, mas o fazem com formas e categorias construídas pelo mundo social, que eles nem escolhem nem inventam (1997).

Como sujeitos teóricos, conceitualizaram uma masculinidade hegemônica, mostrando como uma diversidade de masculinidades, estruturadas por classe, raça, geração e expressão sexual, transitam nas relações de poder entre homens, situando homens diferentes em lugares diferentes na/perante a dominação, mas oprimindo todos ou quase todos, no nível das plenas potencialidades e possibilidades humanas.

Situado historicamente, o conceito da masculinidade hegemônica ilumina como as mudanças constantes nas formas de masculinidade colaboram para reproduzir a dominação e a sujeição, inclusive nas relações internacionais. Desta forma, desloca o eixo da análise de uma certa fixação com a dinâmica e as diferenças "entre homens e mulheres" nas relações de gênero para situar estas relações como recursos a serviço da dominação de grupos específicos, inclusive na hegemonia global do mercado finan- 
ceiro, promovida atualmente por grupos econômicos dos países centrais do capitalismo, na nova desordem mundial.

Desta perspectiva, qualquer tentativa de estudar as relações de gênero precisa avançar além da descrição da evolução de "diferenças culturais" (entre mulheres, ou entre mulheres e homens) e da constatação abstrata da construção social das relações de gênero, para as investigar como elementos da política econômica atual, implicadas numa dinâmica global de dominação de nações e classes sociais e de mercantilização da vida. Alerta, portanto, para a necessidade de avaliar com perspicácia as grandes reformulações que estão se processando nas ideologias e até nas práticas "de gênero" para evitar conclusões baseadas na idéia de que qualquer mudança é positiva, sinal de transformação.
Para além do trabalho intelectual nos estudos de gênero, vale terminar com a advertência do Bourdieu ao feminismo - seduzido, na avaliação dele, pela ilusão da onipotência do pensamento da filosofia pós-moderna, que o feminismo deveria, melhor, desconstruir: Esta ilusão... está dando ímpeto à crença fantasiosa... de que mudamos o mundo mudando as palavras, que a subversão de termos, categorias e discursos é suficiente para subverter ou danificar estruturas objetivas de dominação... crítica discursiva não é automaticamente dotada de eficácia social; condições econômicas e sociais específicas devem ser compostas para que a crítica de categorias se torne crítica social, e devemos lutar coletivamente para realizar estas condições tanto dentro como fora das universidades (Bourdieu, 1997).

\section{Referências bibliográficas}

Beattie PM 2002. Beyond machismos: recent examinations of masculinities in Latin America. Men and Masculinities 4(3):303-308.

Bednarik K 1970. The male in crisis. Knopf, Nova York.

Bourdieu P 1997. Masculine domination revisited. Berkeley Journal of Sociology 41:189-203.

Carrigan T, Connell RW \& Lee J 1987. Hard and heavy: Toward a new sociology of masculinity. In M Kaufman (ed.). Beyond patriarchy: essays by men on pleasure, power, and change. Oxford University Press, Toronto-Nova York.

Connell RW 1987. Gender and power: society, the person and sexual politics. Stanford University Press, Stanford.

Connell RW 1995a. Masculinities. University of California Press, Berkeley-Los Angeles.

Connell RW 1995b. Políticas da masculinidade. Educação e Realidade 20(2):185-206.

Connell RW 1997. La organización social de la masculinidad, pp. 31-48. In T Valdés \& J Olavarría (eds.). Masculinidades: poder e crisis. Ediciones de las Mujeres 24 Isis Internacional, Santiago. 
Connell RW 1998. El Imperialismo y el cuerpo de los hombres, pp. 76-89. In T Valdés \& J Olavarría (eds.). Masculinidades y equidad de género en América Latina. FLACSO, Santiago.

Friedan B 1963. The feminine mystique. W. W. Norton Publishing, Nova York.

Giffin K \& Cavalcanti C 1999. Os homens e a reprodução. Revista Estudos Feministas 7(1,2):53-71.

Haraway D 1988. Situated knowledges: the science question in feminism and the privilege of partial perspective. Feminist Studies 14(3):579-599.

Horowitz G \& Kaufman M 1987. Male sexuality: Toward a theory of liberation, pp. 81-102. In M Kaufman (ed.). Beyond patriarchy: Essays by men on pleasure, power, and change. Oxford University Press, TorontoNova York.

Jessop B 1996. Interpretive sociology and the dialectic of structure and agency. Theory, Culture and Society 13:119-128.

Kaufman M (ed.) 1987. Beyond patriarchy: essays by men on pleasure, power, and change. Oxford University Press, Toronto-NovaYork.

Kaufman M 1987. The construction of masculinity and the triad of men's violence, pp.1-29 In M Kaufman (ed.) Beyond patriarchy: essays by men on pleasure, power, and change. Oxford University Press, TorontoNova York.

Kaufman M 1997. Las experiencias contradictorias del poder entre los hombres, pp. 63-81. In T Valdés \& J Olavarría (eds.). Masculindades: poder e crisis. Ediciones de las Mujeres 24, Isis Internacional. Santiago.

Kimmel MS 1987. The cult of masculinity: American social character and the legacy of the cowboy, pp. 235249. In M Kaufman (ed.). Beyond patriarchy: essays by men on pleasure, power, and change. Oxford University Press, Toronto-Nova York.
Kimmel MS 1997. Homofobia, temor, verguenza y silencio en la identidad masculina. In T Valdés \& J Olavarría (eds.). Masculindades: poder e crisis. Ediciones de las Mujeres 24, Isis Internacional. Santiago.

Kimmel MS 1998. El desarrollo (de gênero) del subdesarrollo (de género): la producción simultánea de masculinidades hegemónicas y dependientes en Europa y Estados Unidos, pp. 207-217. In T Valdés \& J Olavarría (eds.). Masculinidades y equidad de género en América Latina. FLACSO, Santiago.

Laqueur T 1990. Making sex: body and gender from the Greeks to Freud. Harvard University Press, Cambridge, Mass.

Lengermann P \& Niebrugge-Brantley J 1990. Feminist sociological theory: the near-future prospects. In $G$ Ritzer (org.). Frontiers of social theory: the new synthesis. Columbia University Press, Nova York.

Lowe DM 1995. The body in late-capitalist USA. Duke University Press, Durham-Londres.

Ritzer G 1990 (org.). Frontiers of social theory: the new synthesis. Columbia University Press, Nova York.

Seidler VJ 1991. Recreating sexual politics: men, feminism and politics. Routledge, Londres-Nova York.

Vigoya MV 2001. Contemporary Latin American perspectives on masculinity. Men and Masculinities 3(3):237260.

Wernick A 1987. From voyeur to narcissist: Imaging men in contemporary advertising, pp. 277-288. In M Kaufman (ed.). Beyond patriarchy: essays by men on pleasure, power, and change. Oxford University Press, Toronto-Nova York.

Artigo apresentado em 10/1/2004

Aprovado em 2/6/2004

Versão final apresentada em 13/8/2004 